\title{
PREDOMINANCIA DEL TIPO Y MODO RESPIRATORIO EN INDIVIDUOS CON SÍNTOMAS DE ALTERACIÓN TEMPOROMANDIBULAR
}

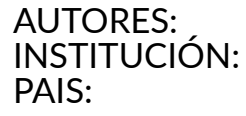

AUTORES: INSTITUCIÓN: PAIS:

Rojas S.M, Parra R.D

Equipo De Investigación De La Motricidad Orofacial Latinoamericana Lima-Perú

\section{RESUMEN}

Objetivo: Determinar previa evaluación la predominancia del tipo y modo respiratorio en individuos que presenten síntomas de alteraciones temporomandibulares. Métodos: Los sujetos de estudios estuvo compuesta por 26 indivíduos, entre 18 e 45 años, portadores de síntomas de alteración temporomandibular como dolor de cabeza, sonidos articulares (click), dolor al bostezar, alteraciones de la oclusión y flacidez de los músculos de la mandíbula; independiente del género. A los cuales se les evaluó el tipo y modo respiratorio predominante en cada sujeto de estudio. Resultados: En relación al tipo respiratorio, se verificó que 22 indivíduos (87\%) presentaron respiración del tipo nasal, de los cuales un 5 (23\%) presentaban dolor de cabeza, 9 (41\%) sonidos articulares, $6(27 \%)$ dolor al bostezar y $2(9 \%)$ alteraciones en la oclusión; 3 (10\%) del total de los sujetos presentaron respiración del tipo oral, de los cuales 1 (33\%) tenían alteraciones en la oclusión y 2 (67\%) flacidez en los músculos de la mandíbula; y 1 (3\%) respiración del tipo mixto el cual presenta alteración en la oclusión. En cuanto al modo respiratorio se observó que de los 26 sujetos analizados, 11 (47\%) presentaron respiración clavicular, de los cuales 3 () presentaban dolor de cabeza, 5 ( ) sonidos articulares y 3 () dolor al bostezar; 9 (33\%) de los individuos presentaron respiración costal, de los cuales 2 ( ) tenían dolor de cabeza, 4 ( ) sonidos articulares, 1 ( ) dolor al bostezar y 2 ( ) alteración en la oclusión; 3 (10\%) respiración Mixta, de los cuales cada uno presentaban dolor al bostezar, alteración en la oclusión y flacidez en los músculos de la mandíbula respectivamente; 1 (4\%) respiración inversa, en el que tenía alteración en la oclusión; y finalmente, 2 (6\%) respiración abdominal, que presentaban dolor al bostezar y flacidez en los músculos de la mandíbula. Conclusión: De acuerdo con el estudio la mayor parte de los individuos analizados con disfunción temporomandibular presentaron respiración del tipo nasal que correspondían los que presentaban en su mayoría el síntoma de sonidos articulares; y respiración del modo clavicular siendo relacionado también con el síntoma de sonidos articulares.

Palabras clave: Sistema estomatognático, Articulación temporomandibular, Tipo de Respiración, Modo de Respiración

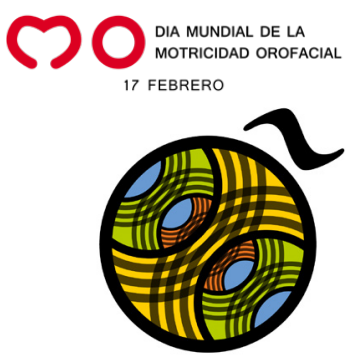

